\title{
Glycyrrhetinic Acid Modified Silicon
}

\section{Phthalocyanine for Liver Cancer Targeted}

\section{Photodynamic Therapy}

Jiyoung Kim, Sanghee Lee and Kun Na*

Department of Biomedical-Chemical Engineering, The Catholic University of Korea, 43 Jibongro, Wonmi-gu, Bucheon-si, Gyeonggi-do, 14662, Republic of Korea 


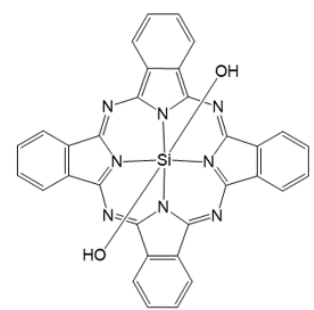

Silicon phthalocyanine dihydroxide $(\mathrm{SiPC})$

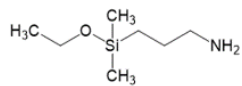

3-(Ethoxydimethylsilyl)propylamine (APDES)

Pyridine, $140{ }^{\circ} \mathrm{C}$, $\mathrm{N}_{2}$ purge

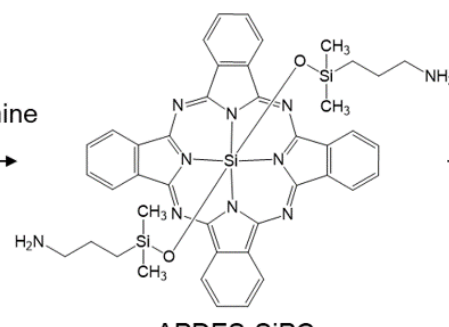

APDES-SiPC
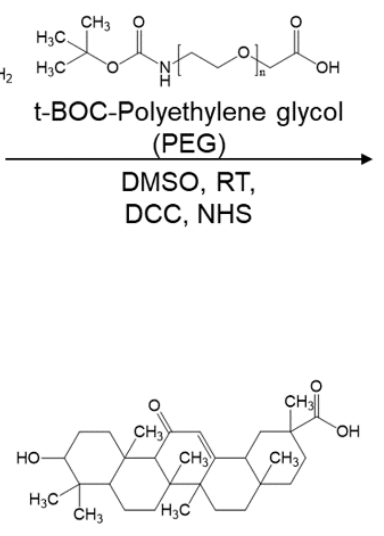

Glycyrrhetinic acid (GA)

DMSO, RT, DCC, NHS

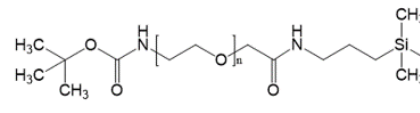

20 mM TFA, RT

PEG-APDES-SiPC
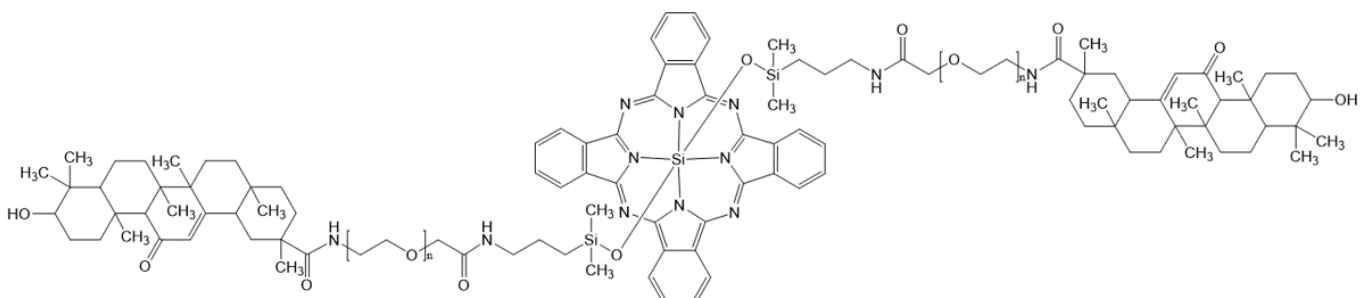

Si

$\mathrm{CH}_{3}$

GA-PEG-APDES-SiPC

Figure S1. Synthesis procedure of GA-PEG-APDES-SiPC.

2 

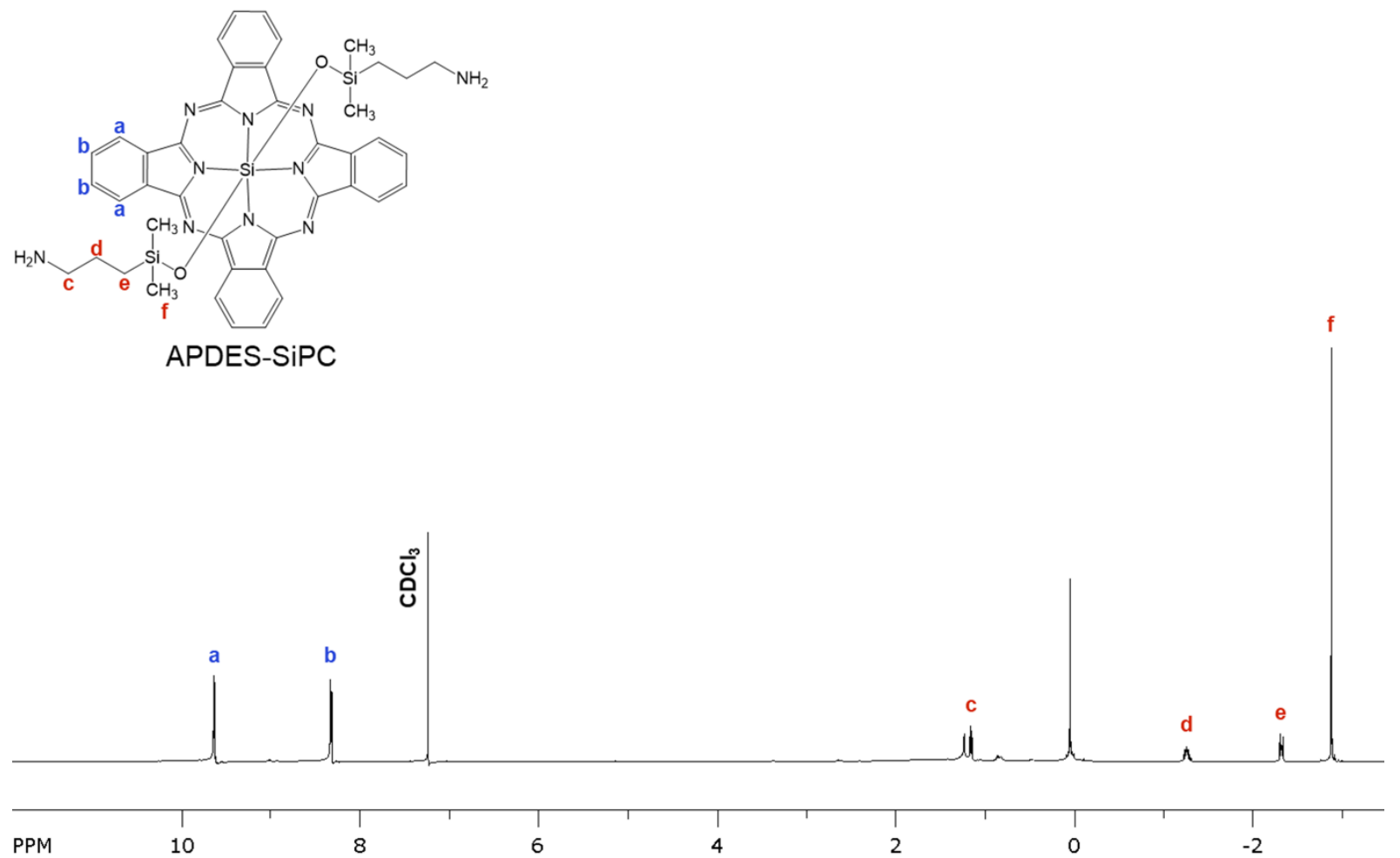

PPM

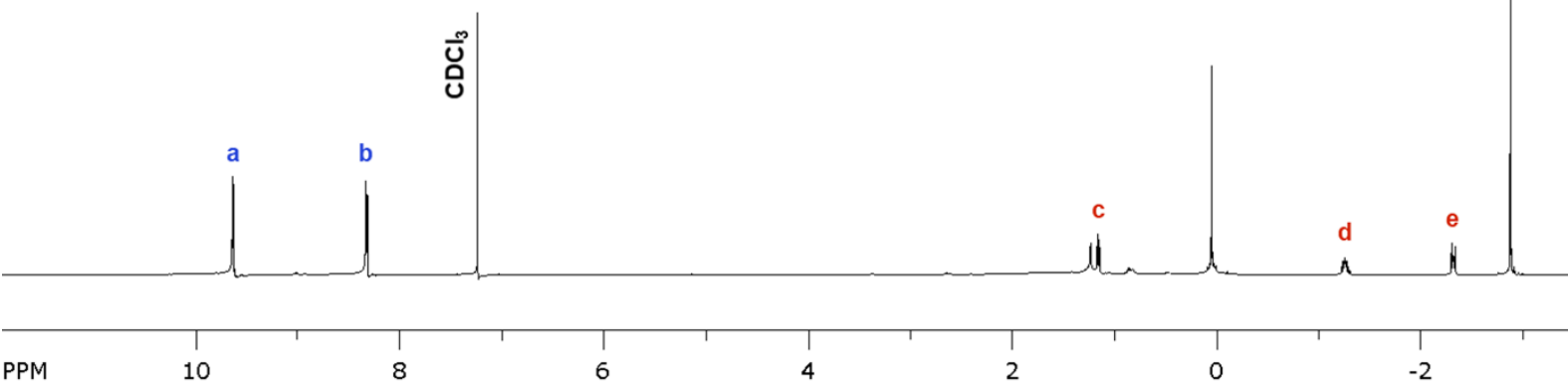

Figure S2. ${ }^{1} \mathrm{H}-\mathrm{NMR}$ analysis of APDES-SiPC in deuterated chloroform $\left(\mathrm{CDCl}_{3}\right)$. 


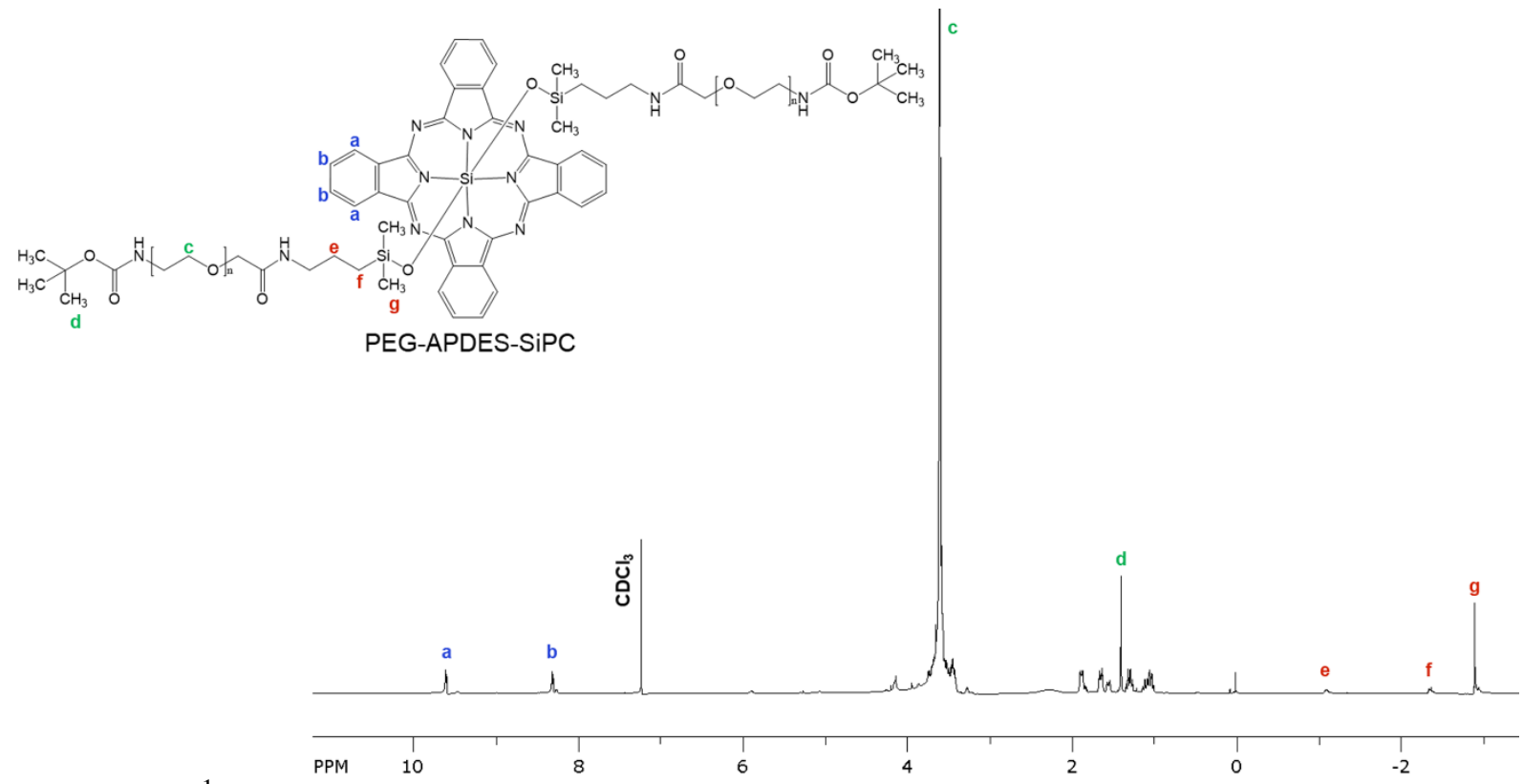

Figure S3. ${ }^{1} \mathrm{H}-\mathrm{NMR}$ analysis of PEG-APDES-SiPC in $\mathrm{CDCl}_{3}$. 


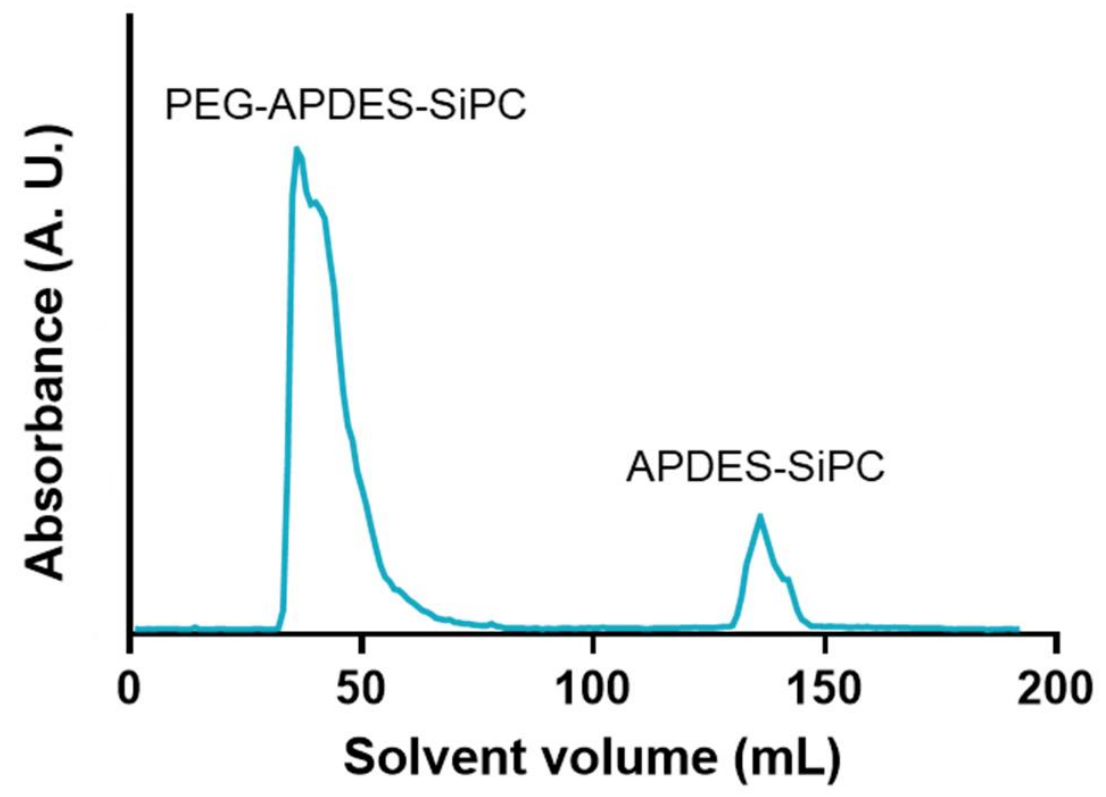

Figure S4. Absorbance measurement at $671 \mathrm{~nm}$ after fractionation of PEG-APDES-SiPC and APDES-SiPC via open column chromatography. 


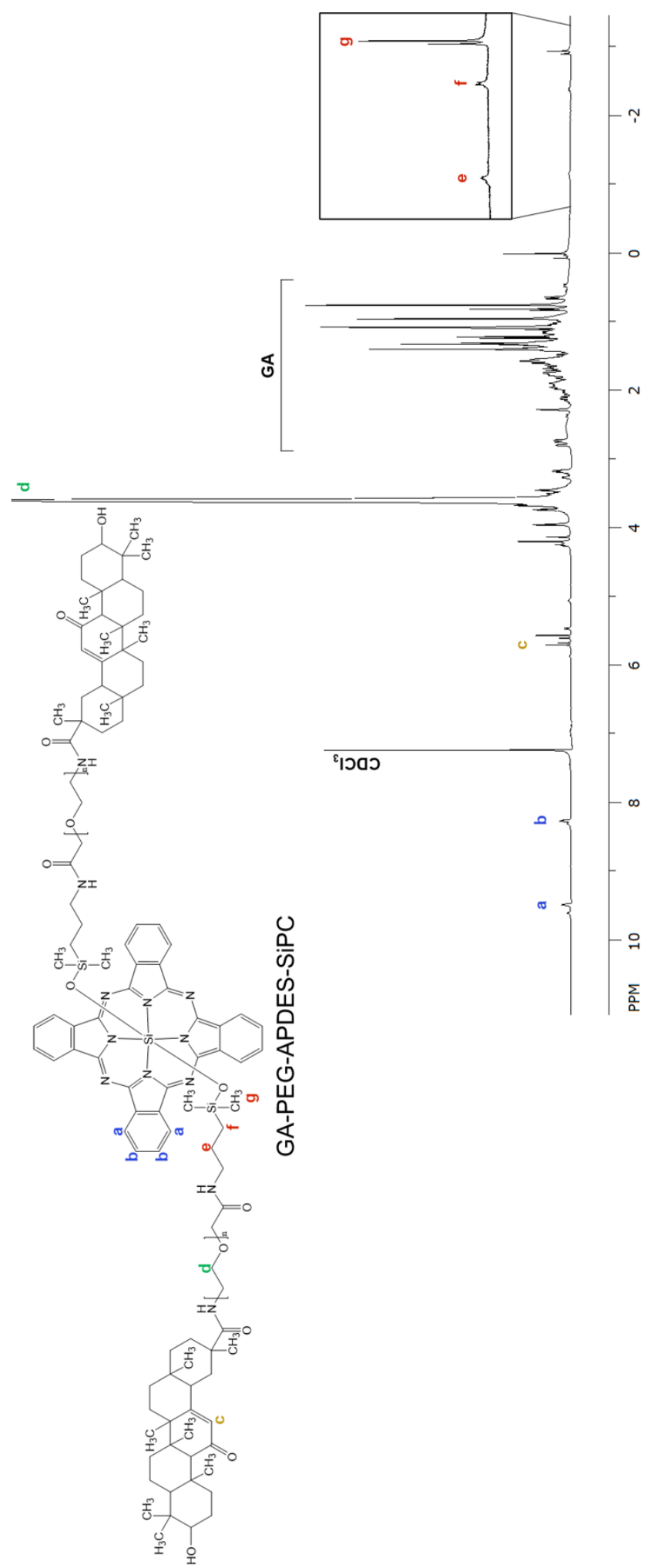

Figure S5. ${ }^{1} \mathrm{H}-\mathrm{NMR}$ analysis of GA-PEG-APDES-SiPC. 


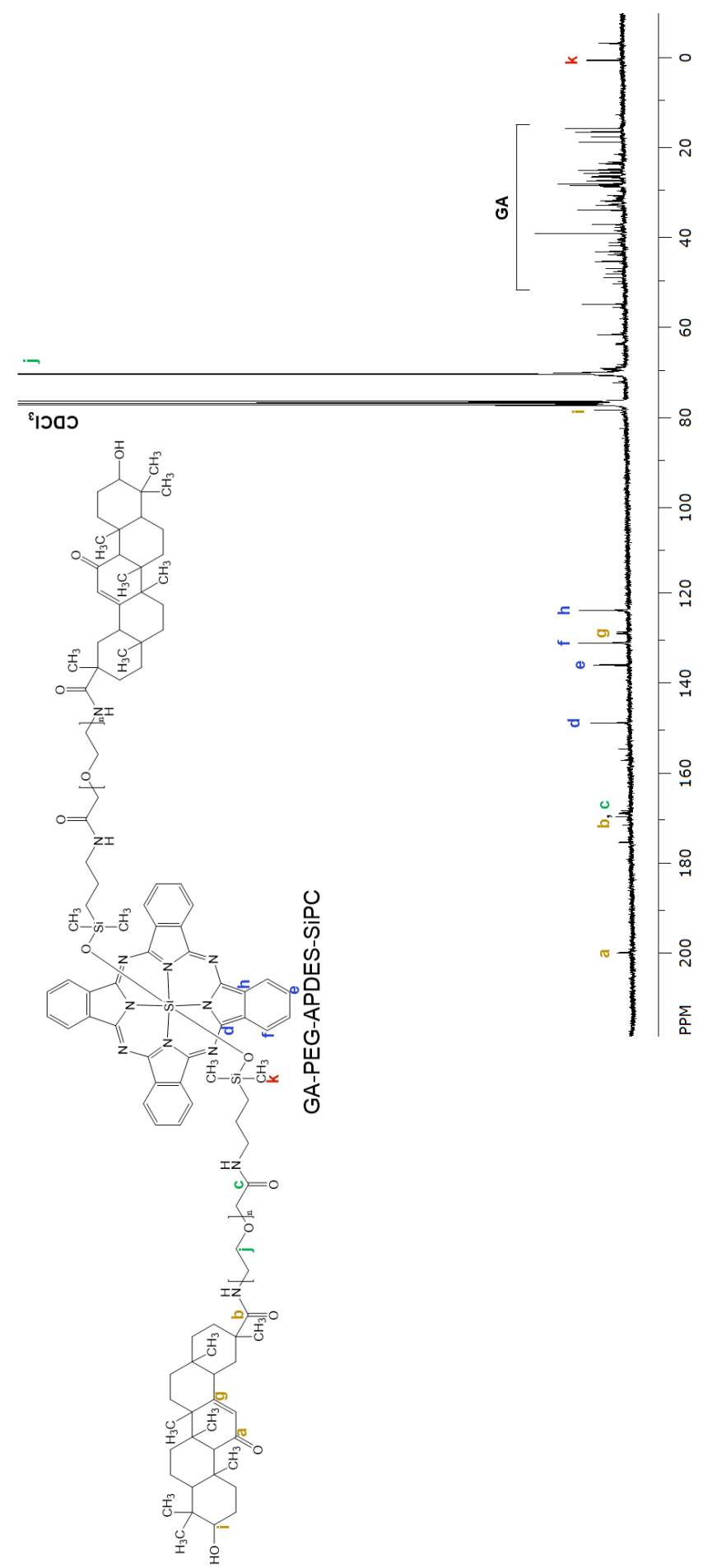

Figure S6. ${ }^{13} \mathrm{C}-\mathrm{NMR}$ analysis of GA-PEG-APDES-SiPC. 


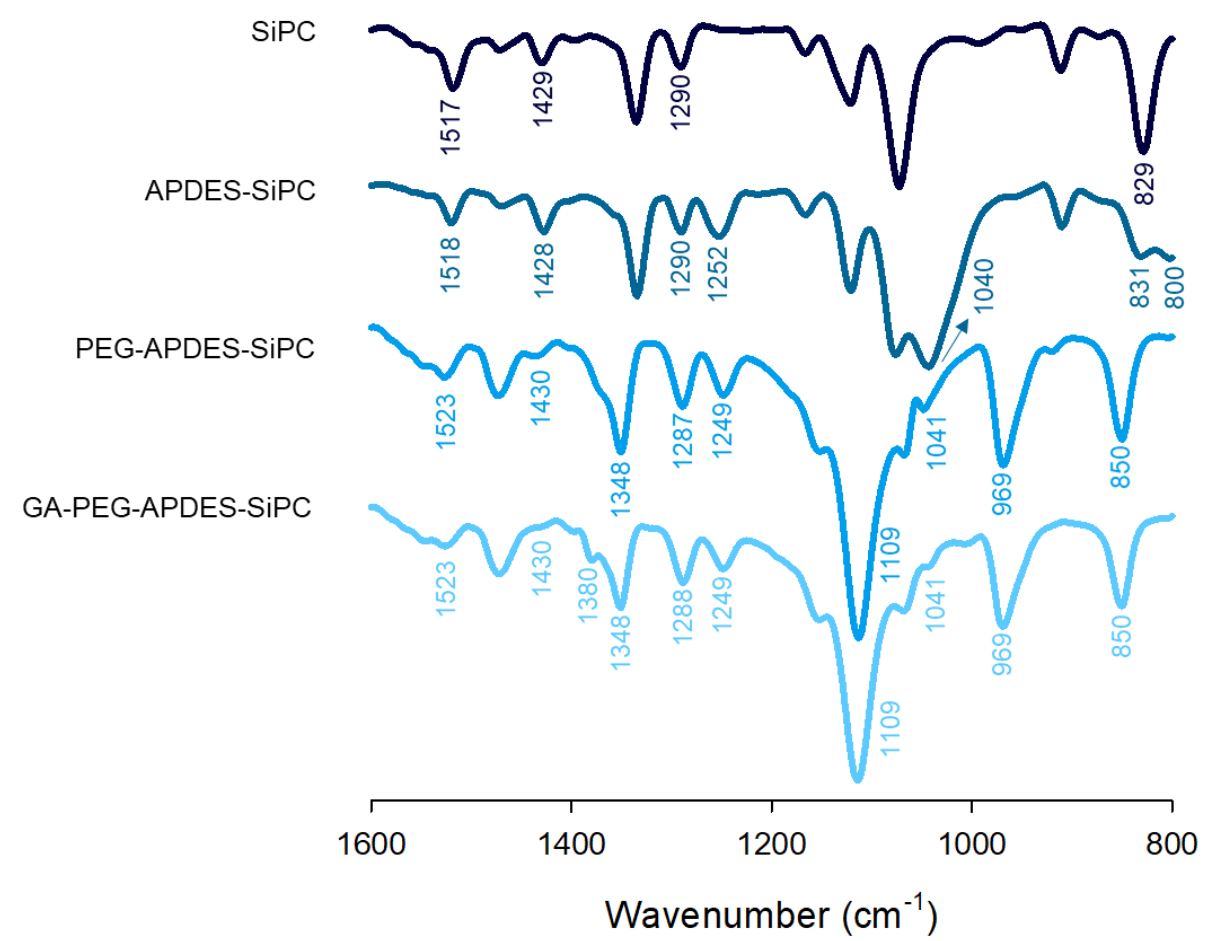

Figure S7. FT-IR spectra of SiPC, APDES-SiPC, PEG-APDES-SiPC, and GA-PEG-APDESSiPC. 
(a)

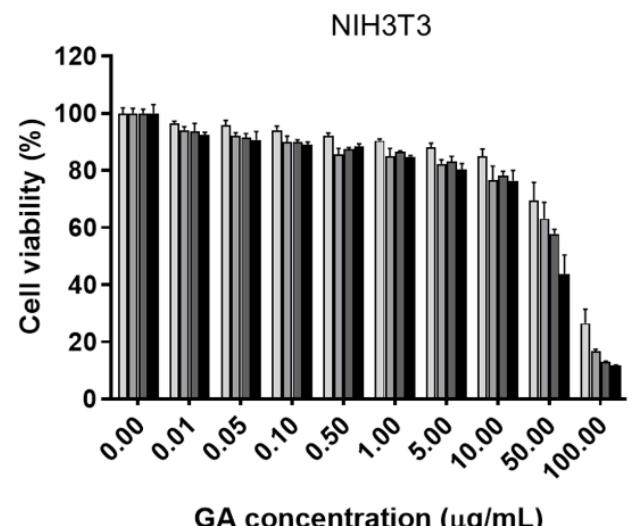

(c)

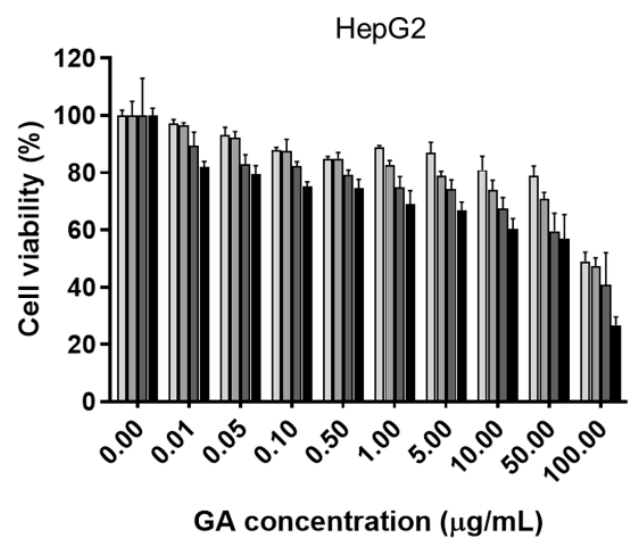

(b)

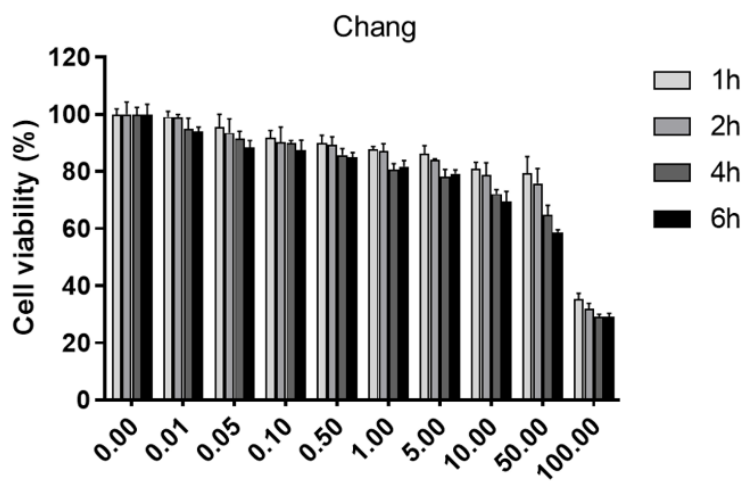

GA concentration $(\mu \mathrm{g} / \mathrm{mL})$

(d)

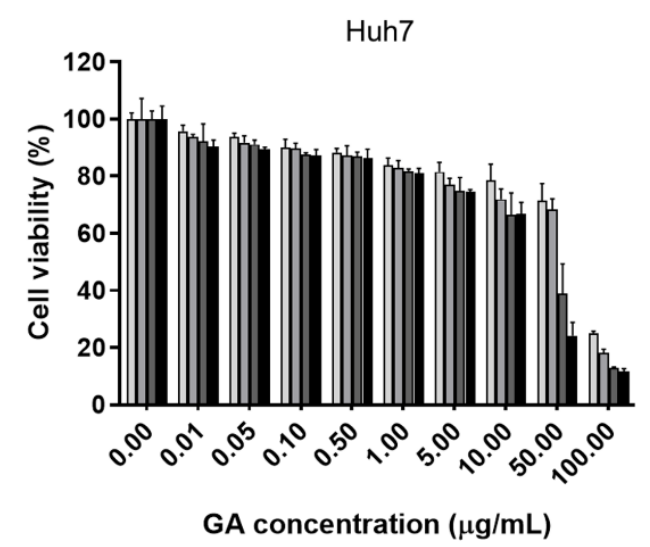

Figure S8. Concentration and time dependent cell viability test of GA. Cytotoxicity analysis of GA (0-100 $\mu \mathrm{g} \mathrm{mL}^{-1}$ ) in (a) NIH3T3, (b) Chang, (c) HepG2, and (d) Huh7 cells treated 1, 2, 4, or 6 hours. (Normal fibroblast, NIH3T3; normal liver cell, Chang; liver cancer cell, HepG2, Huh7). 

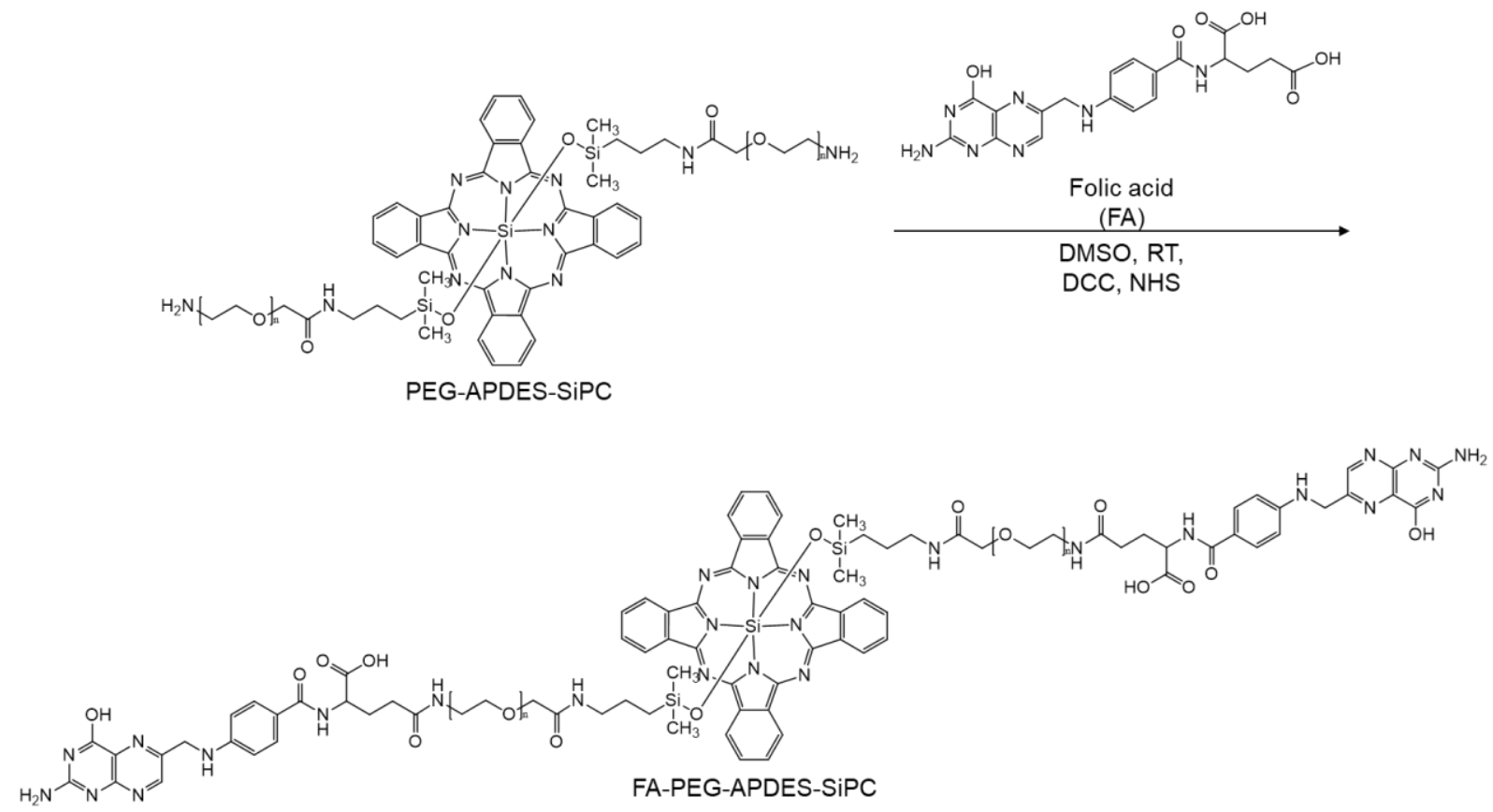

Figure S9. Synthesis procedure of FA-PEG-APDES-SiPC. 

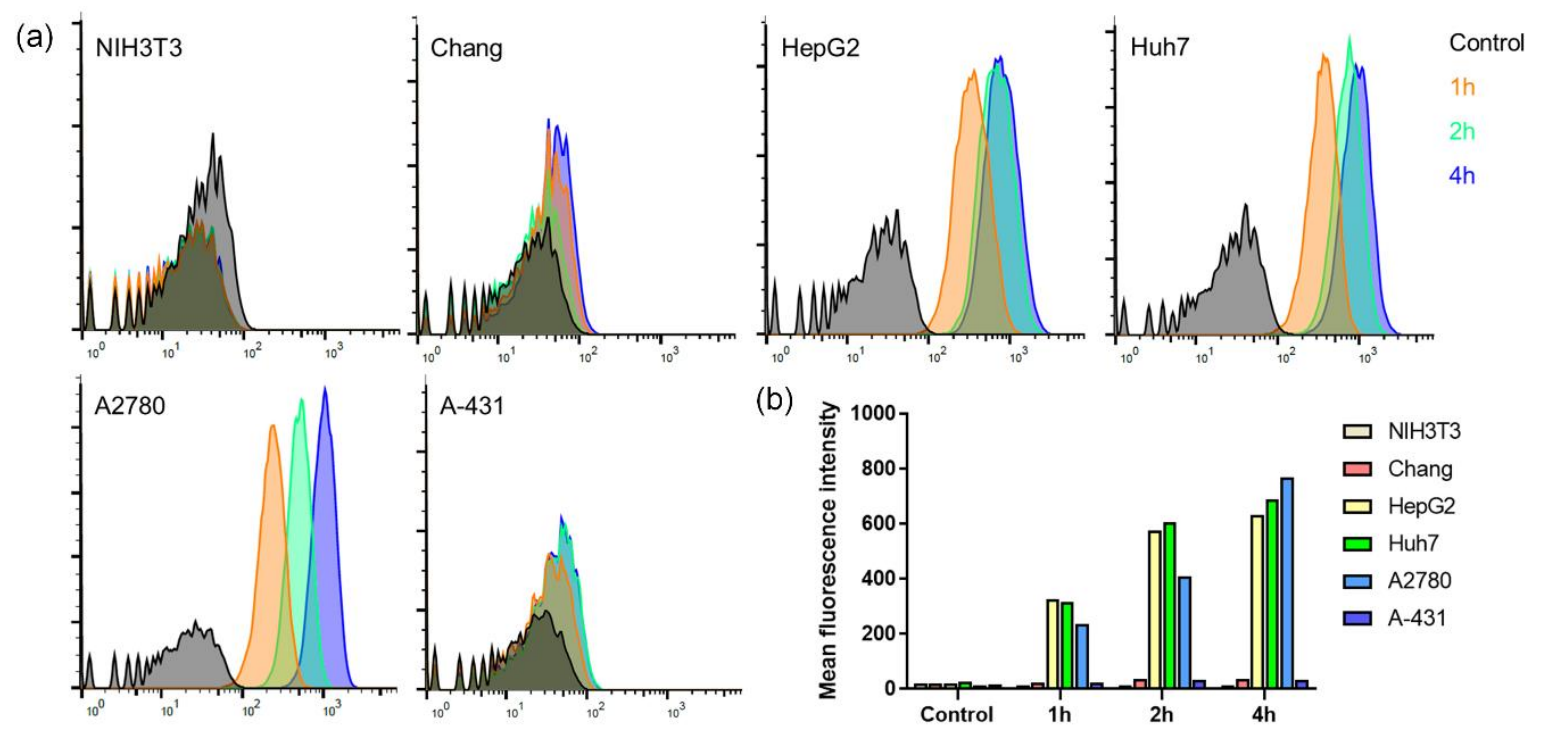

(b)

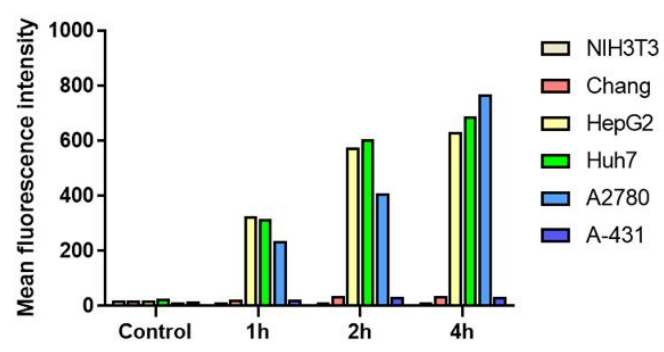

(c)
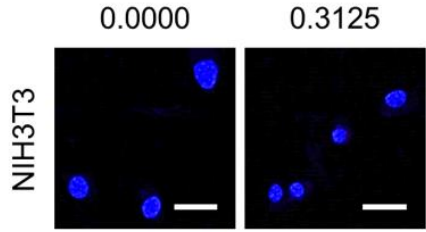

0.6250
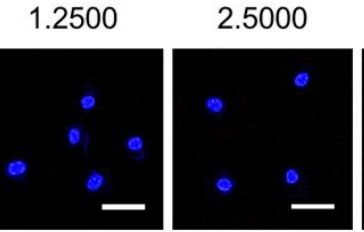

5.0000

10.0000
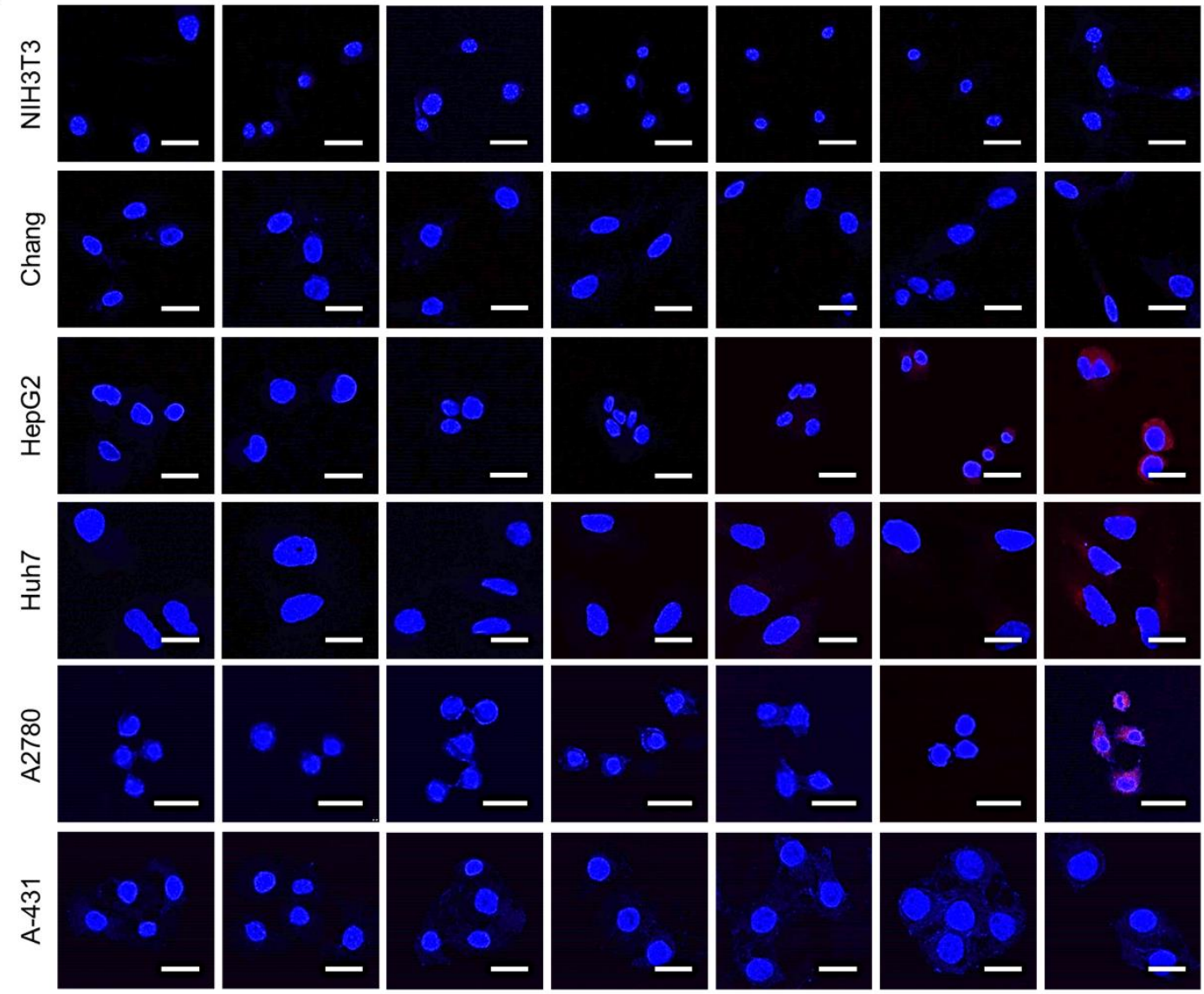

Figure S10. FA receptor mediated cellular uptake test. (a) Flow cytometry analysis in various kinds of FA-PEG-APDES-SiPC treated cells (dose of SiPC, $10 \mu \mathrm{g} \mathrm{mL}^{-1}$ ) for 1, 2, or 4 hours (FA receptor negative, NIH3T3, Chang, A-431; FA receptor positive, HepG2, Huh7, A2780). (b) Mean fluorescence intensity of FA-PEG-APDES-SiPC treated cells. (c) Confocal images of FA-PEG- 
APDES-SiPC treated cells in various concentrations (dose of SiPC, $0-10 \mu \mathrm{gL}^{-1}$ ) for 4 hours. Scale bar, $20 \mu \mathrm{m}$. 


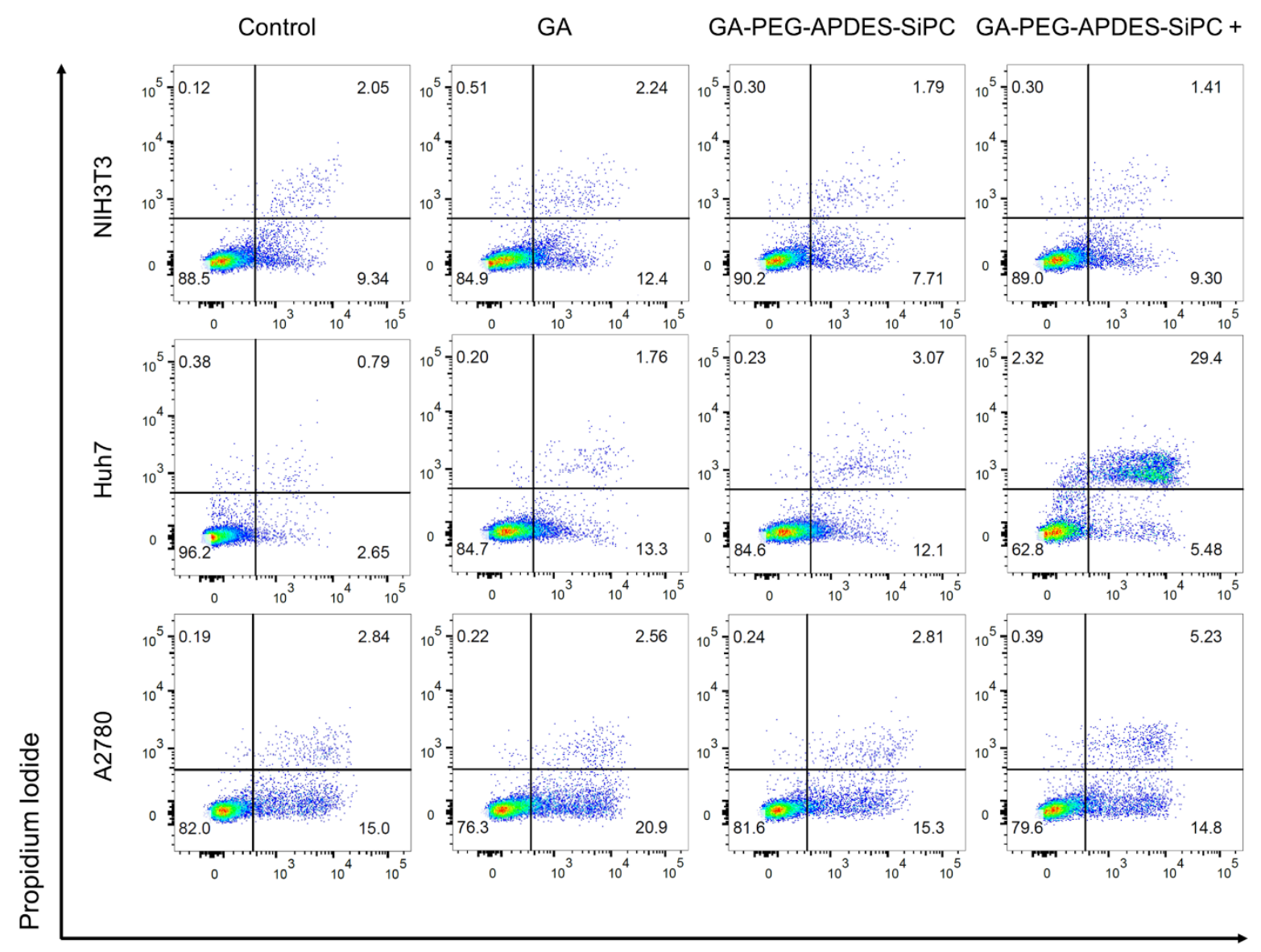

Annexin V-FITC

Figure S11. Annexin V and PI staining after treatment of GA or GA-PEG-APDES-SiPC in NIH3T3 (GA receptor negative, normal), Huh7 (GA receptor positive, liver cancer), and A2780 (GA receptor negative, ovarian cancer) cells. Laser irradiation was indicated with + and irradiation power is $4 \mathrm{~J} \mathrm{~cm}^{-2}$. 
(a)
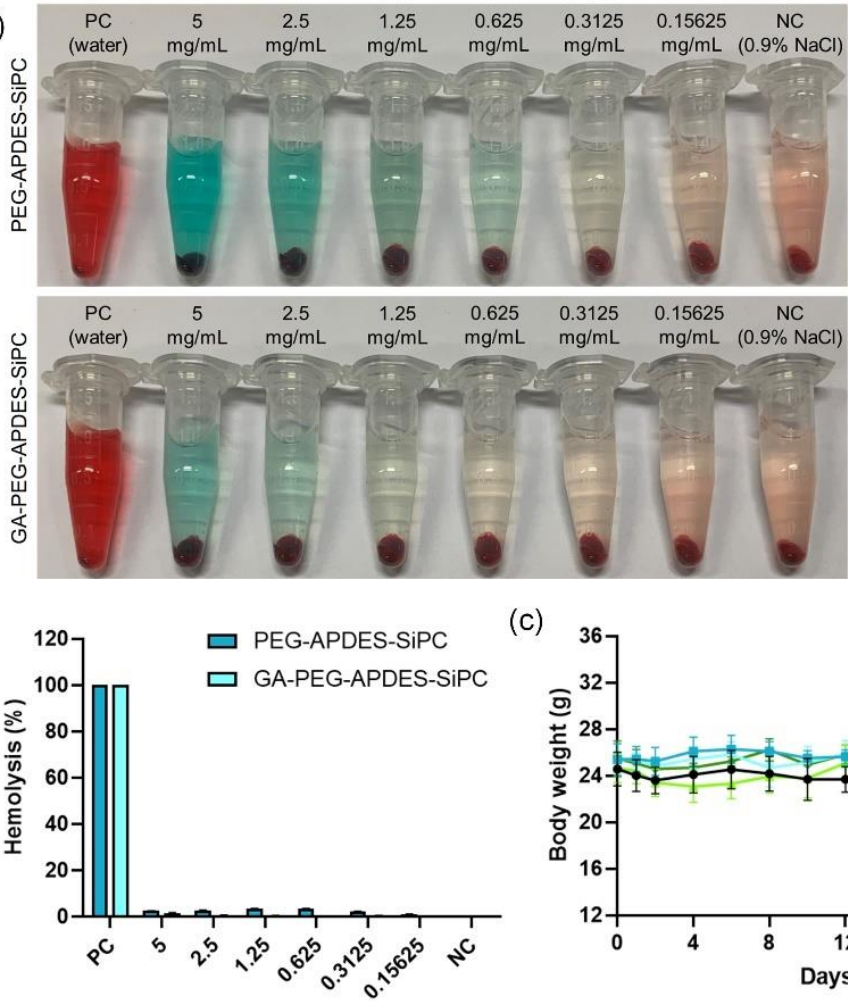

Sample concentration $(\mathrm{mg} / \mathrm{mL})$

(d)

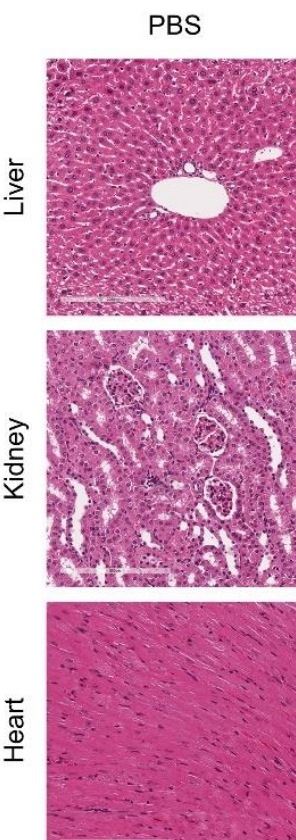

(c)

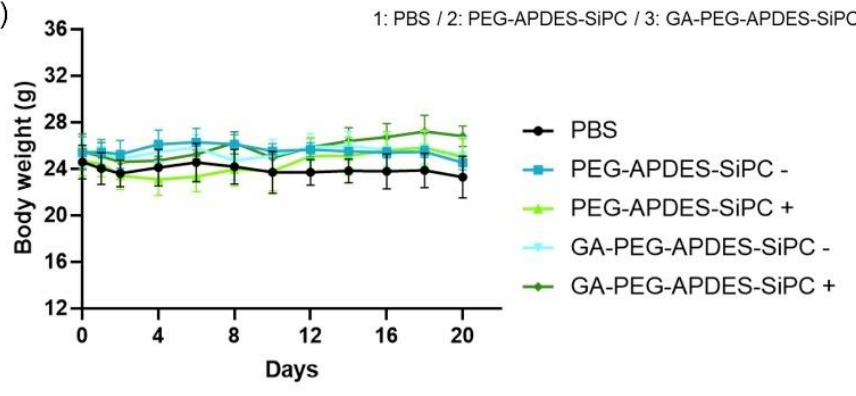

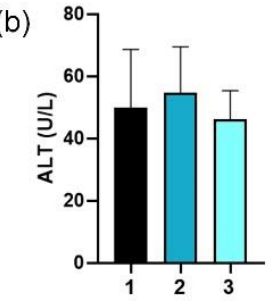
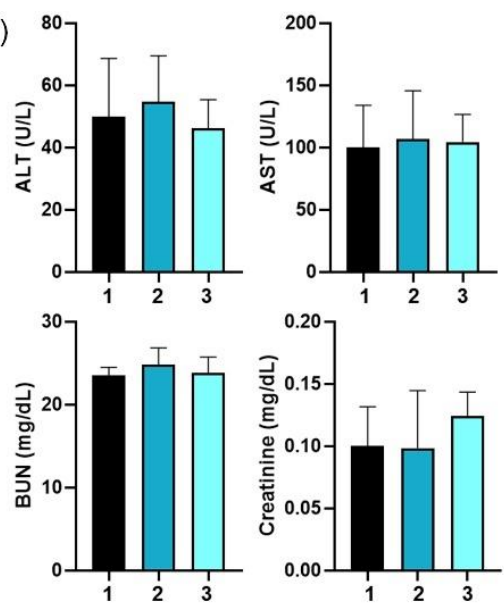

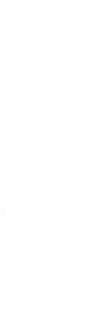

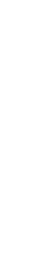

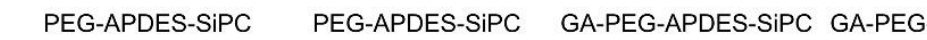

SOCE 
Figure S12. Ex vivo and in vivo toxicity evaluation. (a) Hemolysis analysis of PEG-APDESSiPC and GA-PEG-APDES-SiPC. The red blood cells were treated with various concentrations of samples. Water and $0.9 \% \mathrm{NaCl}$ were selected as positive control (100\% hemolysis) and negative control ( $0 \%$ hemolysis). Hemolysis percentage data are shown as mean \pm SD (n=4). (b) Biochemical liver and kidney function assessment in mice. Data are shown as mean $\pm \operatorname{SD}(n=5)$. (c) Body weights of mice were monitored for 20 days. (d) H\&E staining of major organs from HepG2 tumor-bearing mice. Scale bar, $200 \mu \mathrm{m}$. 